\title{
Quality of Mobile Apps as an Extension Service Delivery Tool to Livestock Based WSHG Members
}

\author{
Jillella Teza ${ }^{1}$, G. R. K. Sharma ${ }^{2}$ \\ ${ }^{1}$ College of Veterinary Science, SPVNR TSU VAFS, Hyderabad, India \\ ${ }^{2}$ College of Veterinary Science, Sri Venkateswara Veterinary University, Tirupati, India
}

\begin{abstract}
Mobile phones can act as a catalyst to rejuvenate the extension services. Recent advancements in the mobile technology are the mobile apps. Mobile apps as an extension services delivery tool could be the most affordable way for farmers to access useful, relevant information. The quality of mobile apps mainly attribute to effective extension service delivery. Thus, present research was formulated to study the quality of mobile apps to improve services to livestock farmers. The study reveals that majority of the respondents were young with basic education, marginal farmers and had medium herd size with medium innovativeness. The quality of the mobile app was good which was measured on different aspects viz. downloading, user interactivity, attraction, holding the interests, visuals and content. There is a need to focus on improving the quality of the mobile apps so that mobile apps could be better utilized in livestock extension system.
\end{abstract}

Keywords: Mobile apps, quality, livestock, extension, women

\section{Introduction}

In present scenario, information had become wealth for the livestock farmers. To provide them with information, reachability have become a tremendous task for the extensional personnel. To reach the unreached, new extension service delivery tools have to be developed. With the advent of Information and Communication Technologies (ICTs), the immense responsibility of the extension services delivery system to disseminate information to the livestock farmers could be fulfilled. ICTs act as an effective and efficient tool to support the livelihoods of rural people providing more subject matter coverage, decision support and direct rural access to information, minimize time and distance barriers [1].

Among various ICT tool, mobile phone mostly used by the farmers when they wanted to avail information related to agriculture and animal husbandry [2]. Mobile phones have many key advantages like affordability, wide ownership, voice communications, and instant and convenient service delivery. So, mobile phones can act as a catalyst to rejuvenate the extension services in the country [3]. Recent advancements in the mobile technology are the mobile apps. As the result of rapid evolution of mobile networks and falling prices and increasing functions of smartphones, there has been a global explosion in the number of m-apps.

Given this dramatic change, mobile apps in general and mobile applications for agricultural and rural development in particular hold significant potential in delivery of various extension services to the information needy farmers. Mobile apps could provide the most affordable way for farmers to access information on new scientific technologies for better farming, markets, and finance which were previously unavailable to them. Mobile app used as an extension services delivery tool should have some quality attributes which would help in providing useful, relevant information and services to the farmers. Though, there have been many studies on the mobile phones, there are a very few studies on the mobile apps.
The quality attributes of mobile apps are needed to be to known to develop the mobile apps which are to be used for the extension service delivery. Thus, present research was formulated to study the qualities of mobile apps so that they could be used to improve services to livestock farmers.

\section{Methodology}

The present study was conducted in Chittoor district of Andhra Pradesh. A total of 100 WSHG members who were involved livestock farming as income generating activity were selected purposively from 4 mandals. From each mandal, 25 WSHG members with livestock based activities were selected purposively. Data was collected with the help of pre tested schedule. The data collected from the respondents were scored, tabulated and analyzed using suitable statistical tools i.e., frequencies and percentages.

\section{Results and Discussion}

\subsection{Personal Profile of the Respondents}

Personal profile of the respondents has the basic information on age, education, family type, family size, land holding, herd size and innovativeness of the WSHG members (Table 1 ).

It could be seen from the Table 1 that majority of the WSHG members were of young age (57.00\%) followed by middle (38.00\%) and old age groups (05.00\%). Young were enthusiastic to access livestock related information through mobile apps. Youth are more receptive to new communication tools and can act as an agent of change. Therefore, gauging their behavior and approach towards utilizing new technologies like mobile apps had utmost importance. Majority of the respondents had good level of education with middle (38.00\%) and high school education (27.00\%). 


\section{International Journal of Science and Research (IJSR) ISSN (Online): 2319-7064 \\ Index Copernicus Value (2013): 6.14 | Impact Factor (2014): 5.611}

Table 1: Personal profile of the Respondents

\begin{tabular}{|c|c|c|c|}
\hline Characteristics & Category & $F$ & $\%$ \\
\hline \multirow[t]{3}{*}{ Age } & Young (up to 35 years) & 57 & 57.00 \\
\hline & Middle (36-50 years) & 38 & 38.00 \\
\hline & Old (above 50 years) & 05 & 05.00 \\
\hline \multirow[t]{6}{*}{ Education } & Functionally literate & 01 & 01.00 \\
\hline & Primary School & 21 & 21.00 \\
\hline & Middle School & 38 & 38.00 \\
\hline & High School & 27 & 27.00 \\
\hline & Intermediate & 05 & 05.00 \\
\hline & Graduate and above & 08 & 08.00 \\
\hline \multirow[t]{2}{*}{ Family type } & Nuclear & 86 & 86.00 \\
\hline & Joint & 14 & 14.00 \\
\hline \multirow[t]{4}{*}{ Family size } & Small (1-3) & 13 & 13.00 \\
\hline & Medium (4-6) & 73 & 73.00 \\
\hline & Large (7-9) & 05 & 05.00 \\
\hline & Very large $(>9)$ & 09 & 09.00 \\
\hline \multirow[t]{6}{*}{ Land holding } & Landless & 08 & 08.00 \\
\hline & Marginal (< 1ha.) & 37 & 37.00 \\
\hline & Small (1.1 to 2 ha) & 27 & 27.00 \\
\hline & Low medium (2.1 to 4 ha.) & 16 & 16.00 \\
\hline & High medium (4.1 to10 ha.) & 06 & 06.00 \\
\hline & Large (> 10 ha.) & 06 & 06.00 \\
\hline \multirow[t]{3}{*}{ Herd size } & Small & 11 & 11.00 \\
\hline & Medium & 72 & 72.00 \\
\hline & Large & 17 & 17.00 \\
\hline
\end{tabular}

This indicates that usage of the mobile apps requires the some level of literacy. Most of the respondents (86.00\%) belonged to the nuclear family, while only 14 per cent of respondents were from joint family. Majority of the WSHG members had a medium family size $(73.00 \%)$ of members with an average family size of 4 members in the family. 37.00 per cent of WSHG members were marginal farmers followed by small $(27.00 \%)$ and medium farmers (22.00\%). Nearly three - fourth of the respondents (72.00\%) belonged to medium herd size followed by large 17.00 per cent and 17 per cent had small herd size category. The WSHG members were with medium level of innovativeness $(55.00 \%)$ towards new extension service delivery tool i.e., mobile app as the mobile phones are ubiquitous and were affordable and accessible to all the sections of the community. These also provide flexibility in accessing information from home or from farm even while at work.

\subsection{Quality of mobile app as extension service delivery} tool: The quality of the mobile app was measured on different aspects viz. downloading, user interactivity, attraction, holding the interests, visuals and content and presented in Table 2.

3.2.1 Downloading: Majority of the WHSG members $(82.00 \%)$ found that the downloading quality of the mobile app was impressive and rated good while 10 per cent as fair and 8 per cent as poor. This indicated that they had ease in the downloading. While developing the app utmost importance was given as downloading the app is first quality of the app which would be considered by the respondents. If the downloading quality of the app is considerably easy then it would help the respondents in accepting the app as of good quality.

3.2.2 User interactivity: The responses on the user interactivity indicated that the majority $(91.00 \%)$ of the WHSG members had rated user interactivity as good. While,7 per cent had rated fair and 2 per cent as poor. The app was very easy in using as the user interactivity was good.

3.2.3 Attractiveness: The responses on attractiveness of the mobile app indicated that majority $(88.00 \%)$ rated it as good. However, 12 per cent and 8 per cent had found it to be fair and poor respectively. Majority opined that app was attractive and had captured the attention [4]. The presentation, usage of attractive visuals and content in simple local language had elicited this response. The suitable videos had added value to the attraction of the modules.

3.2.4 Holds Interests: Sequence in presentation of content in understandable formats with appropriate videos, images and text aroused interest among them. Thus elicited the responses of the respondents as interesting to see (73.00\%), informative and educative (72.00\%), good design (65.00\%) and good video streaming (79.00\%). This indicated that it was appropriate to audience, clear and in logical order, and had simple presentation which was easily understandable to the respondents. Meena et al. (2014) also reported the same findings of arousal of curiosity and interest (62.22\%), simplicity in understanding of information (88.89\%) and logical presentation (76.67\%) [5].

3.2.5 Visuals: Majority of the respondents had perceived that the visuals were apt to the subject matter (92.00\%) with eye pleasing colors $(89.00 \%)$. The visuals should be such that they create interest in audience by capturing their attention and should be informative. The visuals were well sequenced and synchronized with the subject in the text so that the content is easily understood.

3.2.6 Content: Majority expressed that appropriate content with good coverage of all aspects of the subject matter (87\%) and also was up to date (95\%) with inclusion of current information [4], [6]. While, the presentation of content of the subject matter, target group has to be considered. Mainly their knowledge, understanding, culture, perception, information needs etc. In the development of mobile app, enough care was given to the presentation of content by using the appropriate videos and images suiting to the subject.

Table 2: Quality of mobile app as felt by respondents

\begin{tabular}{|c|c|c|c|c|}
\hline $\begin{array}{c}\text { S. } \\
\text { No. }\end{array}$ & Particulars & $\begin{array}{c}\text { Good } \\
(\%)\end{array}$ & $\begin{array}{c}\text { Fair } \\
(\%)\end{array}$ & $\begin{array}{c}\text { Poor } \\
(\%)\end{array}$ \\
\hline A. & Downloading & 82.00 & 10.00 & 08.00 \\
\hline B. & User interactivity & 91.00 & 07.00 & 02.00 \\
\hline C. & Attractiveness & 88.00 & 12.00 & 01.00 \\
\hline D. & Holds Interests & & & \\
\hline 1. & Interesting to see & 73.00 & 25.00 & 02.00 \\
\hline 2 & Informative and Educative & 72.00 & 26.00 & 02.00 \\
\hline 3 & Design & 65.00 & 31.00 & 04.00 \\
\hline 4 & Video streaming & 79.00 & 18.00 & 03.00 \\
\hline E. & Visuals & & & \\
\hline 1. & Apt to subject matter & 92.00 & 06.00 & 02.00 \\
\hline 2. & Eye pleasing colors & 89.00 & 07.00 & 04.00 \\
\hline F. & Content & & & \\
\hline $\mathbf{1}$ & Coverage & 87.00 & 12.00 & 01.00 \\
\hline $\mathbf{2}$ & Up to date & 95.00 & 04.00 & 01.00 \\
\hline
\end{tabular}




\section{Conclusion}

The quality of the mobile apps in terms of downloading, user interactivity, attraction, holding interests, visuals and content in information delivery to the livestock farmer was good. Seeing the pictures, animations and videos in the mobile app had made information value added, more understandable, interesting and attractive. Mobile based applications also helped in stimulating further dialogues or discussions with the neighbours and friends. The livestock farmers were satisfied with it use as an extension service delivery tool to get useful and relevant information in their own language. The ability of mobile applications as an extension service delivery tool in dissemination of value added information to the livestock farmers was note worthy. It will allow self-paced, independent learning and change the role of extension agent from ,Guide by the Side ${ }^{\text {ee }}$ to „Guide behind the Screen". In this era of Information Technology, it seems that the future belongs to mobile applications in information dissemination to the livestock farmers. So, there is a need to focus on improving the quality of the mobile apps so that mobile apps could be better utilized in livestock extension system.

\section{References}

[1] Mruthunjaya, P.Adhiguru, "ICT for livelihood security: a reality check." available at ww.digitaloppurtunity.org/article/view/11395/. pp.22, 2007

[2] N. Mishra, "Livestock information dissemination among farmers through ICT: An exploratory study in Tarai area of Uttarakhand." M.V.Sc Thesis, G.B. Pant Agricultural University, Pant nagar, Uttarakhand, India, 2010

[3] S. Mittal, S. Gandhi, G. Tripathi, "Socio-Economic Impact of Mobile Phones on Indian Agriculture." Available at www.icerier.org/pdf/Working Paper 246.pdf. 2010.

[4] D.S. Rao, "Knowledge Empowerment of Shepherd on Sheep husbandry practices through multimedia modules-An Analysis". M.V.Sc thesis, Sri Venkateswara Veterinary University, Tirupati, 2013

[5] B. S. Meena, R. Kumar, A. Singh, "Effectiveness of multimedia digital video disk on knowledge gain of improved dairy farming practices." Indian J. Dairy Sci. 67(5) pp. 442-445, 2014

[6] S. Monica, V. Randhawa, A.P. Designing, Validation and Evaluation of Self Instructional e-Module on Photography for Online Learning Singh Indian Res. J. Ext. Edu, 11 (1) pp. 13-17, 2011

\section{Author Profile}

Jillella Teza is Ph.D Scholar in College of Veterinary Science, Hyderabad, SPVNR TSU VAFS, Telangana. She pursued her M.V.Sc in Veterinary and Animal Husbandry Extension Education from Sri Ventateswara Veterinary University, Tirupati, Andhra Pradesh.

G. R. K. Sharma is professor and university head Of Department of Veterinary and Animal Husbandry
Extension Education in Sri Venkateswara Veterinary University, Tirupathi Andhra Pradesh. He pursued his Ph.D from the Indian Veterinary Research Institute, Bareilly, Uttar Pradesh 